Original communication

\title{
Police shootings against civilians in Portugal: Contextual, forensic medical and judicial characterization
}

\author{
Ezequiel Rodrigues a, *, Paula Faria b, Agostinho Santos c, d, e, f, Sílvia Fraga ${ }^{\mathrm{g}}$ \\ ${ }^{a}$ Doctoral Program in Forensic Sciences, Faculty of Medicine of Porto University, Alameda Professor Hernâni Monteiro, $4200-319$ Porto, Portugal \\ ${ }^{\mathrm{b}}$ Faculty of Law of Catholic University of Portugal, Rua Diogo Botelho, 1327, 4160-005 Porto, Portugal \\ ${ }^{\mathrm{c}}$ National Institute of Legal Medicine and Forensic Sciences, Department of Pathology, North Branch, Jardim Carrilho Videira, $4050-167$ Porto, Portugal \\ d Faculty of Medicine of Porto University, Department of Legal Medicine and Forensic Sciences, Alameda Professor Hernâni Monteiro, \\ 4200-319 Porto, Portugal \\ e School of Health Sciences of Minho University, Campus Gualtar, 4710-057 Braga, Portugal \\ ${ }^{\mathrm{f}}$ Center of Forensic Sciences, National Institute of Legal Medicine and Forensic Sciences, Largo da Sé Nova, 3000-213 Coimbra, Portugal \\ ${ }^{g}$ EPIUnit - Institute of Public Health, University of Porto, Rua das Taipas, 135, 4050-600 Porto, Portugal
}

\section{A R T I C L E I N F O}

\section{Article history:}

Received 24 July 2014

Received in revised form

14 January 2015

Accepted 20 April 2015

Available online 28 April 2015

\section{Keywords:}

Forensic medicine

Legal medicine

Gunshot wounds

Lethal force

Police

Judicial sentence

\begin{abstract}
A B S T R A C T
The aim of this study was to analyse the circumstances, the forensic assessment and the legal assessment of police shootings of civilians, according to the severity of the victim's injuries. Sixty-nine cases tried in Portuguese criminal courts were analysed. Of the 32 cases that resulted in death, 16 were on the public thoroughfare and 13 were in the victim's vehicle or in third-party vehicles. The majority of the lethal cases occurred when the region of the body hit was the thorax/abdomen. The firearm most frequently used was a semi-automatic $9 \mathrm{~mm}$ pistol. In cases resulting in death police officers involved were convicted whilst those involved in non-lethal cases were acquitted. The results of this study can be taken into account by Portuguese authorities for the implementation of policies that will allow the restriction of firearms use by police officers to situations of imminent danger of death or serious injury and that will make it possible to avoid shooting at fleeing civilians.
\end{abstract}

() 2015 Elsevier Ltd and Faculty of Forensic and Legal Medicine. All rights reserved.

\section{Introduction}

The duties assigned by law to the police mean that police officers may use the force when civilians do not comply voluntarily with their obligations arising from the law or with legitimate orders from the authorities, or when they jeopardise the legal property of the police officers themselves or of third parties. However, the United Nations Code of Conduct for Law Enforcement Officials states that the use of force shall only take place when this is strictly necessary and as required for police officers to do their duty. ${ }^{1}$

In regards to the use of force by the police, discharging firearms at the bodies of civilians stands out. For this to be legitimate, firearms may only be discharged as an extreme measure to protect the life or essential physical integrity of the police officer or of third

\footnotetext{
* Corresponding author. Jardim Carrilho Videira, 4050-167 Porto, Portugal. Tel.: +351 222073850; fax: +351 222083978.

E-mail addresses: ezrodrigues@gmail.com,_pdcf09006@med.up.pt (E. Rodrigues).
}

parties, as stated in the Basic Principles on the Use of Force and Firearms by Law Enforcement Officials. ${ }^{2}$ Although the Code of Conduct for Law Enforcement Officials has no mandatory direct application in any country, Portugal was the only European country that expressly adopted these principles as can be demonstrated in the Portuguese Decree-Law n. ${ }^{\circ} 457 / 99$ of 5 November.

Several studies have shown the actual circumstances under which police officers shoot at civilians, of note being defence against assault $\mathrm{t}^{3-10}$ and making arrests. ${ }^{5,10-13}$

The use of firearms against civilians is the most severe coercive mean used by the police. This severity arises from the high morbidity and mortality associated with it. Taking only the death consequence into account, we have the following data: in Australia, between 1 January 1990 and 30 June 1997, 41 deaths, ${ }^{5}$ and only in Victoria, between 1991 and 1996, 18 deaths, ${ }^{11}$ and between November 1982 and February 2007, 48 deaths $^{14}$; in Germany, between 2000 and 2003, 28 deaths $^{15}$; in France, between 1995 and 1999, 20 deaths $^{16}$; in Spain, between 1999 and 2003, 5 deaths, only by the Guardia Civil ${ }^{17}$; in England and Wales, between 1998 and 2001, 9 deaths, $^{18}$ and between 2004 and 2013, 23 deaths $^{19}$; in the 
United States of America, in New York alone, between 1 January 2003 and 1 April 2007, 42 deaths $^{12}$; in Canada, between 1 January 1999 and 31 December 2009, 139 deaths, and in British Columbia, between 1 January 2000 and 31 December 2009, 30 deaths $^{20}$; in the Netherlands, between 2000 and 2009, 19 deaths. $^{21}$

The consequences of shooting civilians, in terms of the severity of the injuries, depend on the part of the body hit. ${ }^{12,22-24}$ If the shooting results in death, this can be immediate when the brain or the spinal cord are hit, ${ }^{12,23}$ or the heart, even though the effect tends to be less immediate in this case. .2,23,24 $^{2}$

The aim of this study was to analyse the circumstances, the forensic assessment and the legal assessment of shootings of civilians, according to the severity of the injuries, using the criminal proceedings brought against police officers and taken to court.

\section{Materials and methods}

The Portuguese Public Prosecutor's Office (PGR) and the General Inspectorate for Home Affairs (IGAI) operate as formal bodies for monitoring police activity in Portugal and keep records of lethal and non-lethal cases arising from Portuguese police officers discharging firearms at civilians in the line of duty.

In order to carry out this study, we asked the PGR and the IGAI for a list with the identification of all of the criminal proceedings brought against police officers suspected of killing or injuring civilians after discharging firearms in the line of duty, where the cases had been brought to trial, as well as the identification of the courts where we could go through these proceedings.

We received a list of 90 criminal proceedings related to facts occurring between 1991 and 2012. Next, we requested authorisation to go through these cases from the presiding judges. We received permission to go through 70 criminal proceedings but one of these was excluded from our analysis as it was not possible to assess the severity of the injuries. We were not able to consult the other 20 cases: 11, because they could not be found in the courts, and 9 , because no reply was received from the courts. Thus, this analysis took the information from 69 cases into account.

The information was collected by actually going through the criminal proceedings in each court. A form specifically designed for the purpose was used. It was based on collecting the information from the forensic pathology and clinical forensic reports used by the National Institute of Forensic Medicine and Forensic Sciences, Public Institution (INMLCF, I.P.). The following information was collected: socio-demographic characteristics of the victim (gender, age, marital status, occupation, prior criminal records) and of the officer (gender, age, marital status, police force, professional category, criminal record, disciplinary record); contextual characteristics of the shooting (region of the country, time of occurrence, place, type of incident, no. of officers involved, no. of officers shooting, no. of shots, no. of civilians involved, no. of civilians hit, distance of the shot(s), type of weapon, calibre of weapon, projectile used, victim's movements at the time of the shooting, position of the victim relative to the officer, aggression/attempted aggression on the officer or a colleague, type of aggression on the officer); data related to the forensic medical examination (whether or not there was a forensic medical examination, existence or not of injuries), no. of parts of the body affected, identification of the parts of the body affected, internal organs affected, direction of the shots in the victim's body, angle of the shots in the victim's body, need for medical assistance/hospitalisation, severity of the injuries; judicial decision (conviction, acquittal).

Based on the classification that was adopted to the Portuguese Institute of Forensic Medicine and Forensic Sciences, ${ }^{25,26}$ the severity of the injuries arising from the shootings was classified as non-lethal and lethal. Non-lethal severity includes the following degrees: degree 0 - absence of injuries; degree 1 - minimal injuries (e.g., abrasions, broken skin); degree 2 - injuries of medium severity (e.g., laceration, fracture not requiring surgical treatment); degree 3 - severe injuries (requiring surgical treatment); degree 4 - very severe injuries (potentially lethal). Then, the lethal injuries were classified as degree 5 .

A descriptive analysis was carried out. The chi-squared test was used to compare proportions and the Mann-Whitney test to compare continuous variables.

The statistical software used to handle the data was IBM SPSS Version 21.

\section{Results}

\subsection{Characteristics of victims and officers involved}

The victims were mainly male $(n=67)$, with only 2 female victims. There were no statistically significant differences in the socio-demographic characteristics of the victims according to the degree of severity of the injuries $(p>0.05)$ (Table 1$)$.

The police officers involved in the shootings were all male. The police officers who fired the lethal shots were on median $(\mu)$ older $(\mu=35)$ than those who fired non-lethal shots $(\mu=31)(p=0.008)$ and the majority $(\mathrm{n}=25 ; 86.2 \%)$ lived with a partner $(p=0.006)$ (Table 1). It was seen that most of the records describe situations with officers from the National Republican Guard (GNR) and the Public Security Police (PSP). An officer from the Criminal Police (PJ) was involved in only one incident. It was found that the majority of the police officers were involved in carrying out policing duties (91.3\%). Only $7.2 \%$ were in intermediate positions and $1.4 \%$ in leading positions. Only one case was found where the police officer involved had a criminal record. The GNR officers caused lethal injuries in $10(35.7 \%)$ of the 28 cases where they discharged their weapons and the PSP did so in 22 (55\%) of the 40 cases where they fired their weapons.

\subsection{Contextual characteristics of the officer-involved shooting}

Of the 32 cases that resulted in death, 16 were on the public thoroughfare and 13 were in the victim's vehicle or in third-party vehicles.

The type of firearm most commonly used was the semiautomatic pistol $(\mathrm{n}=59)$, calibres $7.65 \mathrm{~mm}(\mathrm{n}=27)$ and $9 \mathrm{~mm}$ $(\mathrm{n}=32)$. Of note is one case of a lethal shooting where the weapon used was a shotgun (calibre 12) loaded with cartridges with rubber buckshot.

No differences were found between non-lethal and lethal shootings as to the part of the country where they occurred (North, Centre, South), the time of the occurrence, the number of civilians and officers involved, the type of incident, the aggression or attempted aggression on the officer or a third party, the number of shots, the distance of the shot and the position of the victim relative to the officer at the time of the shooting $(p>0.05)$ (Table 2$)$.

\subsection{Forensic medical examination results according to injury severity}

A forensic medical examination was carried out in all of the lethal cases $(n=32)$. Of the total of non-lethal cases $(n=37)$, a forensic medical examination was carried out on all but 8 of them.

The existence of bodily injuries on the victim was confirmed at a trial in all of the cases analysed, even if there was no examination.

No differences were found in the severity of the injuries and the direction of the shot in the victim's body $(p=0.196)$ (Table 3$)$. 
Table 1

Characteristics of victims and officers involved according to the injury severity, Portugal (1991-2012).

\begin{tabular}{|c|c|c|c|c|}
\hline & \multicolumn{4}{|l|}{ Injury severity } \\
\hline & Total $\mathrm{n}=70$ & Non-lethal $\mathrm{n}=37$ & Lethal $\mathrm{n}=32$ & p-value \\
\hline \multicolumn{5}{|l|}{ Victims } \\
\hline Age, years median (P25-75) & $24(20-30)$ & $23(19-30)$ & $24(21-30)$ & 0.495 \\
\hline \multicolumn{5}{|l|}{ Marital status, $n(\%)$} \\
\hline Alone & $52(78.8)$ & $27(77.1)$ & $25(80.6)$ & 0.964 \\
\hline Couple & $14(21.2)$ & $8(22.9)$ & $6(19.4)$ & \\
\hline \multicolumn{5}{|l|}{ Occupation, $n(\%)$} \\
\hline High/middle & $16(27.1)$ & $10(27.8)$ & $6(26.1)$ & 0.990 \\
\hline Low & $21(35.6)$ & $13(36.1)$ & $8(34.8)$ & \\
\hline Unemployed & $14(23.7)$ & $8(22.2)$ & $6(26.1)$ & \\
\hline Student & $8(13.6)$ & $5(13.9)$ & $3(13.0)$ & \\
\hline \multicolumn{5}{|l|}{ Prior criminal records, $n(\%)$} \\
\hline Yes & $27(77.1)$ & 20 (76.9) & $7(77.8)$ & 0.958 \\
\hline No & $8(22.9)$ & $6(23.1)$ & $2(22.2)$ & \\
\hline \multicolumn{5}{|l|}{ Officers } \\
\hline Age, years median (P25-75) & $32(28-39)$ & $31(27-37)$ & $35(30-43)$ & 0.008 \\
\hline \multicolumn{5}{|l|}{ Marital status, $n(\%)$} \\
\hline Single & $20(32.8)$ & $16(50.0)$ & $4(13.8)$ & 0.006 \\
\hline Married & $41(67.2)$ & $16(50.0)$ & $25(86.2)$ & \\
\hline
\end{tabular}

With regard to the angle of incidence of the projectile on the victim's body, it was found that, in the lethal cases, this was mainly perpendicular $\left(0^{\circ}\right)$, and that in the non-lethal cases, it was mainly oblique, in a descending direction $(p=0.012)$ (Table 3$)$.

With regard to the part of the body with most severe injuries, it was found that the majority of the lethal cases and the highest incidence of non-lethal cases occurred when the part of the body affected was the thorax/abdomen $(p=0.002)$ (Table 3$)$. It was also found that injuries to the head, neck and thorax were more often lethal than non-lethal, unlike injuries to the abdomen, and that injuries to the face and limbs were never lethal (Fig. 1).

With regard to the exact moment when the police officer shot the victim, it was found that the severity of the injury was most often lethal when the victim was running away and non-lethal when the victim was attacking $(p=0.039)$ (Table 3$)$.

No association was discovered between the distance of the shot and the severity of the injuries $(p=0.947)$ (Table 3$)$. In the majority of the non-lethal cases, the victim was treated in hospital, as opposed to the lethal cases, where the victim died at the scene of the event $(p<0.001)$ (Table 3).

\subsection{Officer-involved shooting: the judicial sentence}

The court sentence handed down for the lethal shootings was conviction in 18 cases (56.3\%) and acquittal in the remaining 14 cases (43.7\%). For the non-lethal cases, the most frequent outcome was acquittal $(p<0.001)$ (Table 3$)$.

With regard to the moment of the shooting, it was found that conviction was the most common outcome when the victim was running away ( $\mathrm{n}=14 ; 60.9 \%)$ and acquittal was the most common when the victim was attacking $(\mathrm{n}=23 ; 50 \%)(p=0.003)$.

As to the position of the victim relative to the police officer at the time of the shooting, it was observed that there is no significant difference with regard to the judicial decision $(p=0.553)$.

Table 2

Contextual characteristics of the officer-involved shooting according to the injury severity, Portugal (1991-2012).

\begin{tabular}{|c|c|c|c|c|}
\hline & \multicolumn{4}{|c|}{ Injury severity } \\
\hline & Total $\mathrm{n}=70$ & Non-lethal $\mathrm{n}=37$ & Lethal $\mathrm{n}=32$ & p-value \\
\hline \multicolumn{5}{|l|}{ Region of Portugal, $n(\%)$} \\
\hline North & $19(27.5)$ & $9(24.4)$ & $10(31.3)$ & 0.759 \\
\hline Centre & $31(35.0)$ & $18(48.6)$ & $13(40.6)$ & \\
\hline South & $19(27.5)$ & $10(27.0)$ & $9(28.1)$ & \\
\hline \multicolumn{5}{|l|}{ Time of occurrence, $n(\%)$} \\
\hline $00: 00-05: 59$ & $27(39.1)$ & $13(35.1)$ & $14(43.8)$ & 0.664 \\
\hline $06: 00-17: 59$ & $19(27.5)$ & $10(27.0)$ & $9(28.1)$ & \\
\hline $18: 00-23: 59$ & $23(33.3)$ & $14(37.8)$ & $9(28.1)$ & \\
\hline \multicolumn{5}{|l|}{ Type of incident } \\
\hline Escape & $23(33.3)$ & $12(32.4)$ & $11(34.4)$ & 0.201 \\
\hline Aggression against officer & $27(39.1)$ & $18(48.6)$ & $9(28.1)$ & \\
\hline Disobeying to stop/arrest & $13(18.8)$ & $4(10.8)$ & $9(28.1)$ & \\
\hline Unintentional shooting by officer & $6(8.7)$ & $3(8.1)$ & $3(9.4)$ & \\
\hline No. citizens involved, median (P25-75) & $2(1-3)$ & $2(1-3)$ & $2(2-3)$ & 0.235 \\
\hline No. officers involved, median (P25-75) & $2(2-3)$ & $2(2-3)$ & $2(2-4)$ & 0.087 \\
\hline \multicolumn{5}{|l|}{ Assault or attempted assault, $n(\%)$} \\
\hline No & $33(50.0)$ & $16(45.7)$ & $17(54.8)$ & 0.622 \\
\hline Yes & $33(50.0)$ & $19(54.3)$ & $14(45.2)$ & \\
\hline No. shots, median (P25-75) & $2(1-4)$ & $3(1-4)$ & $2(1-4)$ & 0.951 \\
\hline Shooting distance (metre), median (P25-75) & $4(2-10)$ & $4(2-10)$ & $4(1-10)$ & 0.874 \\
\hline \multicolumn{5}{|l|}{ Position of the victim, $n(\%)$} \\
\hline In front to the officer & $20(29.4)$ & $13(36.1)$ & $7(21.9)$ & 0.233 \\
\hline Back to the officer & $29(42.6)$ & $12(33.3)$ & $17(53.1)$ & \\
\hline Aside to the officer & $19(27.9)$ & $11(30.6)$ & $8(25.0)$ & \\
\hline
\end{tabular}


Table 3

Forensic medical examination results according to the injury severity, Portugal (1991-2012).

\begin{tabular}{|c|c|c|c|c|}
\hline & \multicolumn{4}{|l|}{ Injury severity } \\
\hline & Total $\mathrm{n}=70$ & Non-lethal $n=37$ & Lethal $\mathrm{n}=32$ & p-value \\
\hline \multicolumn{5}{|l|}{ Shooting direction, $n(\%)$} \\
\hline Front to back & $20(29.0)$ & $13(35.1)$ & $7(21.9)$ & 0.196 \\
\hline Back to front & $29(42.0)$ & $14(37.8)$ & $15(46.9)$ & \\
\hline Right to left & $8(11.6)$ & $2(5.4)$ & $6(18.8)$ & \\
\hline Left to right & $12(17.4)$ & $8(21.6)$ & $4(12.5)$ & \\
\hline \multicolumn{5}{|c|}{ Incidence of shooting in the body, $n(\%)$} \\
\hline Perpendicular & 31 (44.9) & $14(37.8)$ & $17(53.1)$ & 0.012 \\
\hline Oblique top down & $25(36.2)$ & $19(51.4)$ & $6(18.8)$ & \\
\hline Oblique upward & $13(18.8)$ & $4(10.8)$ & $9(28.1)$ & \\
\hline \multicolumn{5}{|c|}{ Most severely injured body regions, $n(\%)$} \\
\hline Head or face or neck & $24(34.8)$ & $11(29.7)$ & $13(40.6)$ & 0.002 \\
\hline Thorax or abdomen & $34(49.3)$ & $15(40.5)$ & $19(59.4)$ & \\
\hline Extremity & $11(15.9)$ & $11(29.7)$ & 0 & \\
\hline \multicolumn{5}{|l|}{ Time of shooting, $n(\%)$} \\
\hline During the victim's attack & $26(38.2)$ & $19(51.4)$ & $7(22.6)$ & 0.039 \\
\hline Victim fleeing & $32(47.1)$ & $13(35.1)$ & $19(61.3)$ & \\
\hline Victim standing still & $9(13.2)$ & $5(13.5)$ & $4(12.9)$ & \\
\hline Miscellaneous & $1(1.5)$ & 0 & $1(3.2)$ & \\
\hline \multicolumn{5}{|l|}{ Shooting distance (metre), $n(\%)$} \\
\hline 0 to 1 & $15(23.8)$ & $8(23.5)$ & $7(24.1)$ & 0.947 \\
\hline 1 to 7 & $24(38.1)$ & $14(41.2)$ & $10(34.5)$ & \\
\hline 7 or more & $24(38.1)$ & $12(35.3)$ & $12(41.4)$ & \\
\hline \multicolumn{5}{|c|}{ Need for hospital care to the victim, $n(\%)$} \\
\hline No & $19(27.5)$ & $2(5.4)$ & $17(53.1)$ & $<0.001$ \\
\hline Yes & $50(72.5)$ & $35(94.6)$ & $15(46.9)$ & \\
\hline \multicolumn{5}{|c|}{ Criminal sentence to the officer, $n(\%)$} \\
\hline Not guilty & 46 (66.7) & $32(86.5)$ & $14(43.8)$ & $<0.001$ \\
\hline Guilty & $23(33.3)$ & $5(13.5)$ & $18(56.3)$ & \\
\hline
\end{tabular}

On analysis of the existence of aggression or attempted aggression on the police officer or a colleague, we discovered that the outcome was mainly a conviction when aggression did not occur ( $\mathrm{n}=16 ; 69.6 \%$ ) and the outcome was acquittal when aggression occurred $(\mathrm{n}=27 ; 61.4 \%)(p=0.032)$.

\section{Discussion}

The lethality rate in the 69 cases analysed was $46.4 \%$. However, our estimate may be overestimated as it was impossible to find out the number of cases of officer-involved shootings of civilians in Portugal. We should also mention that we did not consider in our analysis those cases of shootings that did not result in criminal

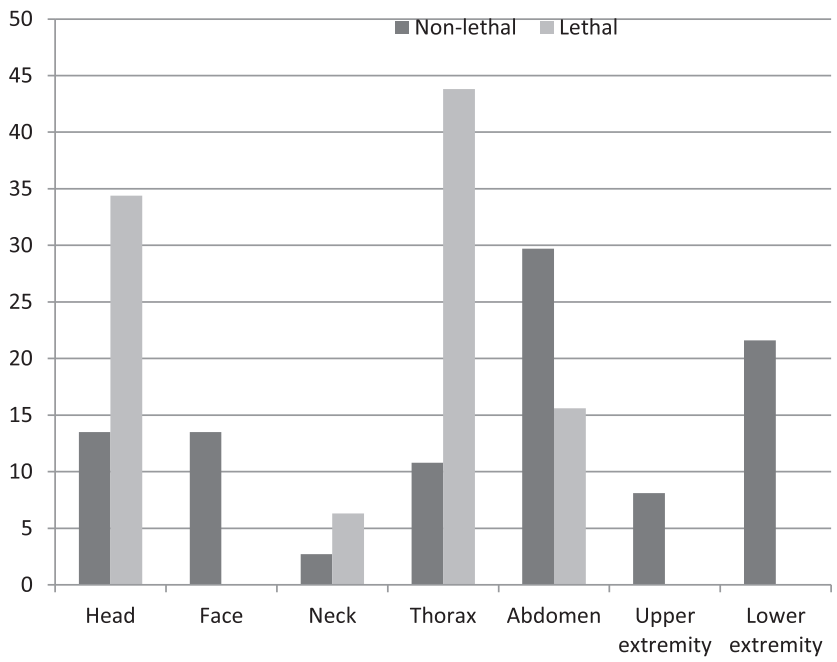

Fig. 1. Injured body regions according to the injury severity (\%), Portugal (1991-2012). proceeding with court hearing. Besides, we were not able to consult 20 cases of the 90 criminal proceedings that occurred in Portugal between 1991 and 2012, which corresponds to around 20\% of the total number of cases although we believe that these cases did not occur in different circumstances than the cases we analysed. Additionally, we are not able to compare our estimate with other countries in where studies were performed using all the population. $6,22,27$

In our study, victims presented a low median age. These values are approximately similar to those observed in a study carried out in some American cities, ${ }^{4,27}$ and also to those found in other studies on police officers discharging firearms. ${ }^{4-6,9,10,12,14}$ Therefore, most police shootings correspond to situations involving young adults. In our study, we observed one case where the victim was a minor, aged 16. Although not so common, other studies have also reported situations involving minors. ${ }^{5}$ With regard to the gender of the victims, the results obtained follow the trend of other studies, which also show that in the vast majority, ${ }^{5,9,12,14,20}$ if not all of the cases, ${ }^{9}$ the victims are male.

The highest percentage of lethal cases occurred with PSP officers (55\%). We were not expecting such result once the Law that regulates the use of firearms (Decree-Law n. ${ }^{\circ} 457 / 99$ of 5 November) is the same for the all Portuguese police forces. Besides, PSP is a civilian police force while the GNR is the Portuguese police force with more of a military bent. Because of that, it could be expected that there would be a philosophy of legal use of firearms in the GNR geared more towards effective performance of their mission and less concerned with the preservation of human life. However, we must point out that the fact that the total number of incidents of the Portuguese police forces shooting on civilians is unknown could limit comparisons between them.

With regard to the places where the shots were fired, the most common were the public thoroughfare and the victim's vehicle or third-party vehicles. As to the place, it is important to emphasize the high percentage of lethal cases in the incidents occurring in 
vehicles. This result may be due to the fact that the officer hits the victim through the structure of the vehicles (glass, metal), which alters the trajectory of the projectiles. Thus, the officer ends up having no control over the shot and much less on the part of the body that is hit. However, this percentage is lower than the percentage of lethal shootings on the public thoroughfare when the victim is on foot. This difference may, once again, be as a result of the circumstances. In the former, the projectile hits the structure of the vehicle before hitting the victim, becoming deformed and slowing down, thus losing power to penetrate the body, unlike what happens in the latter, where the projectile directly hits the victim's body.

The thorax/abdomen was the part of the body most often hit, both in lethal and non-lethal cases. This is in accordance to the results obtained by James \& Melissa, ${ }^{12}$ if only the thorax is taken into account, but differs from the results obtained by Ahmad \& et al., ${ }^{28}$ in which deaths were due to chest injuries. The thorax/ abdomen is the part of the body most often hit probably because to the larger surface area and it is thus more likely that the shot will hit here. On the other hand, it is the part of the body that is easier to get considering the line of sight when the officer raises the weapon to eye level to take the target. In the lethal cases according to the specific part of the body, it should be noted that the highest percentage was in the chest and head. Valerie \& et al. ${ }^{22}$ showed that there was no significant statistical difference in the rate of lethal cases among the people hit in the head and those hit in other parts of the body. Also of note in this study is the nonexistence of any death in the cases where the most serious injury was to the upper or lower limbs. The Portuguese police teaches officers that if they have to discharge a firearm against civilians, whenever possible, they should try to hit parts of the body that do not have vital organs, preferably the legs, even in the face of threats of death or serious injury, in order to preserve the life of the suspects to the utmost. The results of this study prove the correctness of this doctrine.

The most common angle of incidence of the projectile in the victim's body was in the perpendicular in lethal and non-lethal cases. There has not been much investigation on the angle of incidence of shootings. However, the results obtained suggest that it could be interesting to investigate more deeply into the angle of incidence of the projectiles in order to establish the correct trajectories and, thus, better understand the circumstances of the shooting and discover the truth behind the events.

Our results showed that the highest number of the shootings occurred when the victim is running away. In these circumstances, considering that the victim's action is not an imminent danger to the officer or third parties, according to the Portuguese Law (Decree-Law n. ${ }^{\circ} 457 / 99$ of 5 November) the officer would not be expected to fire because it is not legal. Taking into account only the lethal cases, we found that the majority of the shots were also fired when the victim was running away. These results are unexpected because police officers would be expected to fire more lethal shots when they were being attacked than when they were not as, during an attack, they can act on the spur of the moment without having time to take a controlled shot. There are studies showing that the reaction time of police officers increases and the precision of shooting decreases when they are directly attacked by aggressive offenders, due to the anxiety that such an attack causes. ${ }^{29-32}$ However, we should mention that, as in another countries, Portugal has adopted the Basic Principles on the Use of Force and Firearms by Law Enforcement Officials and created a law that specifies the conditions that must be met for the use of firearms. Comparing Portugal to another European countries, it is known that Germany and Spain have, for instance, similar law to Portugal although Germany is less restrict than Portugal.
We found no significant statistical difference between lethal and non-lethal cases according to the distance of the shot. Therefore, this study shows that the lethal nature of single-projectile shots is not associated with the distance between the police officer and the civilian in question. Conversely, the study by Michael ${ }^{6}$ shows that the percentage of lethal cases decreases as the distance of the shot increases. However, in the case of the shooting with less lethal projectiles, it can be assumed that the short distance of the shot had a major influence on the death of the victim, as in the study by Czeslaw \& et al. $^{7}$

In the majority of the cases (lethal and non-lethal) the judicial decision acquitted the police officer involved in the shooting and approximately $30 \%$ of the acquittals corresponded to lethal cases. In the majority of cases, officers were convicted when the victim did not attack or attempt to attack the officer or a colleague. However, when it was proved that the victim attacked the officer they were acquitted. It seems to indicates that Portuguese courts place value on the fact that the victims of the officer-involved shooting had at some point attacked or attempted to attack the officers or third parties, even if this was before the officers fired their weapons.

The main limitation of this study arises from the fact that we could not find all the cases of officer-involved shootings against civilians in Portugal. This was because there is no systematic record of all of the cases. As far as we know this is the first study performed in this country on this topic. Although the limitations, we are convinced that information of the criminal proceedings was privileged access to a source that is difficult to receive authorisation for.

We must emphasize that we are characterizing the situation of a country that has a very restrictive law on the police shooting. Also, our study results highlight the need to be established more clear legal rules that restrict the use of firearms to situations of imminent danger of death or of serious bodily injury and there must be greater investment on legal, technical and psychological training for police officers, so that they may refrain as far as possible from shooting at parts of the body where there are vital organs, making firearms, in fact, the last resort for police officers doing their job.

\section{Ethical approval}

Not required.

Funding

None.

\section{Conflict of interest}

The authors hereby declare that they had no financial support or other conflicts of interest regarding the publication of this article.

\section{Acknowledgements}

We would like to thank Professor Teresa Magalhães, Head of the Porto Delegation of the National Institute of Legal Medicine and Forensic Sciences, for her help in the preparation of the data collection file and in our request for authorisation to go through the criminal proceedings in the courts. We would also like to thank Professor Carla Lopes, from the Universidade of Porto Institute of Public Health for helping us to define our methodology and data processing. Sílvia Fraga is the recipient of a Post Doc grant from Fundação para a Ciência e a Tecnologia (SFRH/BPD/97015/2013).

\section{References}

1. UN. Code of conduct for law enforcement officials. Adopted by General Assembly resolution 34/169 of 17 . December 1979.

2. UN. Basic principles on the use of force and firearms by law enforcement officials. In: Adopted by the 8th United Nations Congress on the Prevention on Crime 
and the Treatment of Offenders, Havana, Cuba, 27 August to 7 September 1990. Cuba: OHCHR; 1990.

3. James JF. Police use of deadly force: research and reform. Justice Q 1988;5: 165-205.

4. Jonathan RS, James WM, Deon EB. Factors related to killings of felons by police officers: a test of the community violence and conflict hypotheses. Justice $Q$ 1993; 10:417-40.

5. Vicki D. Police shootings 1990-97. Trends Issues Crime Crim Justice 1998;89: $1-6$.

6. Michael DW. Hitting the target (or not): comparing characteristics of fatal, injurious, and noninjurious police shootings. Police Q 2006;9:303-30.

7. Czeslaw C, Mariusz K, Christian J, Stanislawa K-N, Weronika K. Case-study of fatal gunshot wounds from non-lethal projectiles. Forensic Sci Int 2008;178: $213-7$.

8. Kris M, John RM. Suicide by cop among female subjects in officer-involved shooting cases. I Forensic Sci 2011:56:664-8.

9. Amber RN, James RG. Death certification of "suicide by cop". J Forensic Sci 2011;56:1657-60.

10. Dragana K, Stuart DMT, James RPO. Analysis of fatal police shootings: time, space, and suicide by police. Crim Justice Behav 2012;39:1107-25.

11. Kilie P, John AG. A profile of deaths in custody in Victoria, 1991-96. J Clin Forensic Med 2000;7:82-7.

12. James RG, Melissa P-S. Firearms deaths by law enforcement. J Forensic Sci 2009;54:185-8.

13. Cordelia NO, Matthias IO, David TLBS. An analysis and report of custodial deaths in Nebraska, USA: part II. J Forensic Leg Med 2012;19:465-9.

14. Dragana K, Stuart DMT, James RPO. Mental illness among police fatalities in Victoria 1982-2007: case linkage study. Aust New Zel J Psychiatry 2010;44:436-68.

15. Thomas F. The use of firearms by police officers in Germany. In: General Inspectorate for Home Affairs, editor. The use of firearms by police officers. Lisbon: General Inspectorate for Home Affairs; 2003. p. 131-47.

16. Charles D. The use of firearms by police officers in France. In: General Inspectorate for Home Affairs, editor. The use of firearms by police officers. Lisbon: General Inspectorate for Home Affairs; 2003. p. 177-85.

17. Lourenzo PF. The use of firearms by police officers in Spain. In: General Inspectorate for Home Affairs, editor. The use of firearms by police officers. Lisbon: General Inspectorate for Home Affairs; 2003. p. 187-209.
18. David B, Anna Q, Alan B. Police shooting as a method of self-harming: a review of the evidence for "suicide by cop" in England and Walles between 1998 and 2001. Int J Sociol Law 2004;32:349-61.

19. Independent Police Complaints Commission. Deaths during or following police contact: statistics for England and Wales 2012/2013. Independent Police Complaints Commission; 2014.

20. Rick P. The police use of deadly force in british Columbia: mental illness and crisis intervention. J Police Crisis Negot 2011;11:57-71.

21. Kubat B, Duijst W, Van de Langkruis R. Dying in the harms of Dutch governmental authorities. J Forensic Leg Med 2013;20:308-11.

22. Valerie B, Joseph LA, James AM, Marcie-jo K, Daniel AP. Lethality of firearmrelated injuries in the United States population. Ann Emerg Med 2000;35: 258-66.

23. Vicent JMDM, Suzana ED. Manual de Patología Forense. José MSP, José IMB, Angelines CL Maria SRC, traductors. Madrid: Díaz de Santos; 2003.

24. Pekka S, Bernard K. Knight's forensic pathology. 3rd ed. London: Arnold; 2004.

25. Hamonet CL, Brugere JM, Margeat H. Étude comparée des résultats obtenus avec une nouvelle méthode tridimensionelle d'évaluation et le baréme du Concours Médical dans 124 cas d'expertises judiciaires. Gazette du Palais; 1991. p. $15-23$.

26. Teresa M. Estudo Tridimensional do Dano Corporal: Lesão, Função e Situação (Sua Aplicação Médico-Legal). Coimbra: Coimbra Editora; 1998.

27. Johannes K, Jon S. Police use of firearms in Norway and Sweden: the significance of gun availability. Police Soc 2003;13:429-39.

28. Ahmad M, Nabil A, Ibrahim H, Afo A, Zvi L, Moshe M, et al. Blunt and penetrating injuries caused by rubber bullets during the Israeli-Arab conflict in October, 2000: a retrospective study. Lancet 2002;359:1795-800.

29. Raôul RDO. Reality-based practice under pressure improves handgun shooting performance under pressure. Ergonomics 2008;51:261-73.

30. Arne N, Raôul RDO. Effects of anxiety on handgun shooting behavior of police officers: a pilot study. Anxiety Stress Coping Int J 2010;23:225-33.

31. Arne N, Raôul RDO. Training with anxiety: short- and long-term effects on police officers' shooting behavior under pressure. Cogn Process 2011;12: 277-88.

32. Arne N, Geert JPS, Raôul RDO. Shoot or don't shoot? why police officers are more inclined to shoot when they are anxious. Emotion 2012;12:827-33. 